COMMENT

\title{
Cartilage destruction in rheumatoid arthritis
}

\section{S Gay, S Kuchen, R E Gay, M Neidhart}

Ann Rheum Dis 2002;61 (Suppl II):ii87-ii87

S ynovial fibroblasts represent an important source of matrix degrading enzymes mediating joint destruction in rheumatoid arthritis. ${ }^{1}$ In our search for new pathways for the activation of synovial fibroblasts we have detected endogenous retroviral sequences, like the line 1 element $(\mathrm{Ll}){ }^{2}$

To study the functional role of Ll we transduced synovial fibroblasts with $\mathrm{Ll}$ constructs and showed that Ll induces a number of crucial transcription factors for the activation of these cells. Most significant was the induction of $\mathrm{p} 38 \delta$. At present $\mathrm{p} 38$ $\delta$ has not been explored in detail, although several interesting pathways have been examined. The fact that p38 $\delta$ phosphorylates various transcription factors, including ATF-2, Elk-1, and SAP-1, and that it could be shown that the ATF-2 pathway is potentially linked to the induction of certain oncogenes as well as to the production of matrix degrading metalloproteinases ${ }^{3}$ has put this molecule at the focus of our interest.

Because inhibition of $\mathrm{p} 38 \alpha$ and $\beta$ has been the centre of interest for new therapeutic targets by the industry we studied the expression of the different isoforms at sites of joint destruction ${ }^{4}$ and showed that synovial cells appear to be activated not only by a cytokine dependent pathway but also by a cytokine independent pathway. The latter fact may explain the observation that anticytokine treatments of rheumatoid arthritis do not abolish joint destruction completely.

\section{Authors' affiliations}

S Gay, S Kuchen, R E Gay, M Neidhart, WHO Collaborating Center for Molecular Biology and Novel Therapeutic Strategies for Rheumatic Diseases, Department of Rheumatology, University Hospital, Gloriastrasse 25, CH-8091 Zurich, Switzerland

Correspondence to: Steffen.Gay@ruz.usz.ch

\section{REFERENCES}

1 Pap T, Müller-Ladner, Gay RE, Gay, S. Fibroblast biology - role of synovial fibroblasts in the pathogenesis of rheumatoid arthritis. Arthritis Res 2000;2:361-7.

2 Neidhart M, Rethage J, Kuchen S, Kunzler P, Crowl RM, Billingham ME, et al. Retrotransposable LI elements expressed in rheumatoid arthritis synovial tissue: association with genomic DNA hypomethylation and influence on gene expression. Arthritis Rheum 2000;43:2634-47.

3 Tsai EY, Falvo JV, Tsytsykova AV, Barczak AK, Reimold AM, Glimcher $\mathrm{LH}$, et al. A lipopolysaccharide-specific enhancer complex involving Ets, Elk-1, Sp 1 and CREB binding protein and p300 is recruited to the tumor necrosis factor alpha promotor in vivo. Mol Cell Biol 2000;20: 6084-94.

4 Neidhart M, Kuchen S, Rethage J, Semayer CA, Gay RE, Gay S. Reply to comment by Brooks WH. Autoimmune diseases may result from inappropriate RNA polymerase III transcription. Arthritis Rheum 2002;46:1412-13. 